\title{
MALE MATING SUCCESS AND FEMALE PREFERENCE FOR MULTIPLE TRAITS IN THE TWOLINE PUPFISH (CYPRINODON BIFASCIATUS)
}

by

ANNA M. LUDLOW ${ }^{1)}$, MURRAY ITZKOWITZ and DAVID R. BAIRD ${ }^{2,3)}$

(Department of Biological Sciences, Lehigh University, Bethlehem, Pennsylvania, 18015, USA)

(Acc. 7-IX-2001)

\begin{abstract}
Summary
Using the twoline pupfish (Cyprinodon bifasciatus), a species with a resource-based polygynous breeding system, we examined male mating success in the wild, and we experimentally investigated effects of male body size and substrate type on female association patterns in the laboratory. Our purpose was to (a) identify the traits contributing to male reproductive success in the field, (b) measure preferences for each trait independently in the laboratory, and (c) determine the relative importance of each trait. Field observations revealed that substrate type was the main determinant of male reproductive success: males defending territories on rocks mated significantly more often than males defending territories on silt or sand. Laboratory experiments supported the field data, and revealed that the female preference for substrate type was independent of male body size effects. When given a choice between two males matched for size but differing in the type of substrates they were defending, females preferred the male on the rocky substrate over the male on the sandy substrate. Laboratory experiments also revealed a female preference for larger males when substrate type was held constant. Finally, when females were presented with a choice between a large male on a sandy substrate and a
\end{abstract}

1) Corresponding author; current address: Environmental and Evolutionary Biology, Bute Building, University of St Andrews, Fife, KY16 9TS, Scotland, UK; e-mail address: aml2@st-andrews.ac.uk

2) Institute of Cell, Animal and Population Biology, University of Edinburgh, West Mains Road, Edinburgh EH9 3JT, United Kingdom.

3) We would like to thank John Nyby, Craig Williamson, Robert Jaeger, John Leiser and three anonymous reviewers for valuable comments on earlier drafts of this manuscript. This research was supported by a Theodore Roosevelt grant from the American Museum of Natural History and a CONACYT studentship from the Mexican government, both awarded to Anna Ludlow. 
small male on a rocky substrate, no clear preference emerged. We provide several interpretations for this result, and we argue that both traits may be strong predictors of the male's competitive ability.

\section{Introduction}

Most research on female mate choice has focused on female preferences for a single male characteristic (see Andersson, 1994 for a review). However, empirical work reveals that females often use multiple cues to select their mates, usually a combination of both morphological characteristics and material resources (Kodric-Brown, 1983; Thornhill, 1983; Price, 1984; Thompson, 1986; Lifjeld \& Slagsvold, 1988; Petersen, 1988; Cote \& Hunte, 1989; Bisazza et al., 1989). This is most apparent in polygynous breeding systems, where males have access to females mainly by defending a resource essential to female reproduction.

Few studies have tried to determine the relative importance of different male characteristics contributing to female mate choice. Backwell \& Passmore (1996) showed that female fiddler crabs selected males primarily on the basis of body size, but further discriminated among large males on the baisis of burrow quality. Dale \& Slagsvold (1996) found that female pied flycatchers had independent preferences based upon male color, nest quality, and male mating status. When faced with a conflict between two male characteristics, females paid more attention to the one on which the males differed the most.

Here we experimentally examined the relative importance of male characteristics and material resources in the female mating preferences of the polygynous twoline pupfish (Cyprinodon bifasciatus). We identified correlates of male reproductive success on the basis of field observation s and then experimentally tested whether these correlates affected female association patterns. Previous work with poeciliid fish (Kodric-Brown, 1993) and other species of the genus Cyprinodon (A.M. Ludlow, unpubl. data) found that female association (time spent in close proximity; see Gabor, 1999) with males is a good predictor of mating preferences. In other species of Cyprinodon, females appear to select males on the basis of size and the type of substrate type within their territories. For example, female variegated pupfish (C. variegatus) prefer larger males (Draud, 1996), and female Pecos pupfish $(C$. pecosensis) prefer to spawn with males on rocky substrates (Kodric- 
Brown, 1977, 1983). In the twoline pupfish, males defending rocks also appear to be more successful, and a preliminary experiment revealed that the reproductive success of males was improved simply by placing rocks within their territories (A.M. Ludlow, unpubl. data). Here we extend these preliminary observations by testing whether males defending territories on rocks have higher mating success than males defending territories on other substrates. Also, because body size appears to be a good indicator of competitive ability in other Cyprinodon (Draud, 1996), we predicted that female twoline pupfish would prefer larger males.

To see whether females showed independent preferences for male size and the presence or absence of a rock within the territory, we provided females with a choice between two males and manipulated one of these traits while keeping the other constant. We predicted that when body size was held constant, females would prefer to approach a male on a rocky substrate over a male on a sandy one. Conversely, when differences in substrate quality were held constant, we predicted that females would prefer to approach a larger male. The relative importance of these two cues was tested by pitting the cues against one another. For example, females were given a choice between a small male on a preferred substrate (rock) and a large male on a non-preferred substrate (sand).

\section{Study animal}

The twoline pupfish (Cyprinodon bifasciatus) is an endemic fish of the Cuatro Cienegas basin in Coahuila, northern Mexico. C. bifasciatus is found mainly in thermal springs $\left(30-34^{\circ} \mathrm{C}\right)$, and their immediate outflows, and is restricted to habitats with constant year-round temperature. Ludlow (2000) performed the only in-depth behavioral analysis of this species and observed it to have a resource-based polygynous breeding system in which males attract spawning females mainly by defending a substrate suitable for female oviposition. Smaller or competitively inferior males can occasionally obtain matings by adopting alternative mating strategies, such as satellite and sneaker behaviour. Females typically spawn on two types of substrate: bare limestone rock and silt. Males defend territories on the shallow shores of springs on small rocks and silt, which also serve as courtship areas.

Females are generally found in large feeding groups in the deeper regions of the springs. Prior to spawning, females swim toward the shallow areas 
and visit several territories. When a female enters a territory, spawning can occur either with or without courtship by the male. When courtship occurs, it is brief and involves circling movements in which the male pursues the female. Females indicate willingness to spawn by nipping on the bottom and pausing. Following this cue, males join females and the pair proceeds to spawn. Spawning lasts only a few seconds and is characterized by the pair adopting an S-shaped posture, after which, with a jerky movement, the eggs and sperm are released.

When spawning is completed, the female leaves the male's territory. No parental care of the eggs is exhibited by either parent, but eggs are indirectly defended by the male as a result of territorial defense (other conspecific individuals are the most common egg predators). A female typically lays one egg per spawning event, although females often spawn repeatedly with the same males. Both males and females typically spawn with several mates per day.

\section{Methods}

\section{Field observations}

Field observations were conducted on two populations in separate springs (Poza Escobedo and Poza la Becerra) in April and May, 1997 and 1998. The springs were qualitatively similar, except for the presence in Poza la Becerra of a large limestone embankment on one side of the spring. The rest of the spring (and the entire habitat in Poza Escobedo) consisted of finegrained silt and sand, which extended to variable depths. Isolated limestone rocks of different sizes were scattered on the silt and were typically defended by one or more fish depending on the size of the rock. Males also defended small areas of silt between the rocks in both springs. The two sites appeared quite similar with respect to availability of territories. No estimates of population size were made.

\section{Male focal observations}

We conducted focal observations on randomly selected territorial males in both springs. All observations were conducted in the intervals 0900-1030 and 1330-1500 h. We observed 50 males in each locality (data pooled from both years), with observations equally divided between the morning and afternoon. Before data collection, each male was observed for $5 \mathrm{~min}$ to determine the extent of his territory, which was defined as the area in which he spent $90 \%$ or more of his time during the observation period. We did not mark territories because fish were observed only once. To avoid observing the same fish on different days, males within a certain area were observed on the same day, and that area of the spring was not observed again. Prior observations indicated that some males remained in their territories for at least 3 weeks. 
After the 5 min-period during which territories were defined, we conducted focal observations on individual males for $15 \mathrm{~min}$. During these observations, we recorded the total number of females that descended into the substrate and spawned with the male. Once a pair descended to spawn, one or multiple spawns could occur. In the latter case, the female moved a short distance after each spawning event, but remained within the male's territory. When multiple spawns occurred, we recorded the total number of individual spawning events. Because females typically lay one egg per spawning event, the total number of eggs received by males could be estimated from the total number of individual spawning events.

After the behavioral observations were completed, we placed a plastic ruler within the male's territory in order to estimate his size. We defined 5 size categories a priori (category I: 3-4 cm; II: 4-5 cm; III; 5-6 cm; IV: 6-7 cm: V: 7-8 cm) and assigned each male to one size category after we observed him beside or above the ruler. However, because some males did not swim close enough to the ruler to estimate their size, we could only obtain such estimates for 45 males in Escobedo and for 37 males in La Becerra (data from both years). We used this method for estimating size instead of measuring the fish because collecting the fish without severely disrupting the breeding grounds was impossible.

\section{Female preferences: laboratory experiments}

Experiments were conducted from May to July 1998. Fish were wild-caught at Poza la Becerra in April and June 1998 and kept in aquaria at $27-32^{\circ} \mathrm{C}$ near their natural habitat, under natural illumination, with dawn around $0630 \mathrm{~h}$ and dusk around 1930. The aquarium water was obtained from the spring where the fish were collected. Fish were sorted by sex and kept in separate stock tanks where they were fed ad libitum flake food twice per day (Tetra-Min flakes for tropical fish). The fish were left undisturbed for 3 weeks prior to the beginning of the experiments, to allow them to acclimate to the laboratory conditions. Before the experiments began, the length of all fish, from the tip of the snout to the end of the caudal fin, was measured to the nearest $0.1 \mathrm{~mm}$.

We investigated association patterns instead of mating preferences, because allowing the fish to interact directly may have resulted in extreme aggression between males. For example, Draud (1996) found that when variegated pupfish males are placed together in a tank without any physical barriers, they generally engage in aggressive encounters that result in severe physical injuries to the defeated male. Because male-male interactions could have interfered with the mating decisions of females, we separated the males from each other and from the female using transparent Plexiglas partitions. This procedure allowed us to examine female preferences independently of male competitive ability. Males did not seem to affect each other's behavior towards the female, and no threat or aggressive displays between males were observed during the experiments.

\section{Experimental design}

The set-up for all experiments consisted of eight 40-1 aquaria in which five sections of equal size were marked on the bottom of the tank. The sections at each end of the tank were separated from the three center sections by clear Plexiglas partitions. These end sections constituted the compartments in which individual males were placed. The three center sections combined constituted the female compartment. By using the markings on the outside bottom of the center section, we were able to record the location of the female (i.e. left 
of center, center, right of center). A thin opaque partition was placed adjacent to the clear Plexiglas partitions in order to prevent visual communication between the fish in the three compartments before the beginning of the experiment.

For each experimental trial, a female was randomly selected from the stock tank, measured, and placed in the center compartment, where she was left to acclimate for $24 \mathrm{~h}$. Two males were then selected from the stock tanks, introduced into the end compartments of the experimental tank, and allowed to acclimate for $10 \mathrm{~min}$. In previous work with other Cyprinodon species (Itzkowitz, pers. comm., A.M. Ludlow pers. obs.), females were more likely to mate when isolated from other fish for $24 \mathrm{~h}$, whereas males were ready to court and spawn with females after only 5 minutes in the tanks.

In two experiments, males of different sizes were chosen to examine the effect of male size on female association patterns, while in another, they were chosen to be of 'equal' length. Males were considered equal in size when the smaller male's body length was at least 95\% that of the larger male. In unequal pairings, the length of the smaller male was $50-85 \%$ of the larger male's. These size ranges were used because of the limitation of our stock population. We did not use pairs in which the smaller male's length was $86-94 \%$ of the larger male's, nor pairs in which the smaller male was less than half the larger's size. In all experiments, the female was smaller than both males, and the largest male was never more than $2.5 \mathrm{~cm}$ larger than the female.

After the acclimation period, the opaque partitions were removed, and the female could see both males. We quantified the amount of time that the female spent adjacent to each male compartment by recording her position within the three central sections every $5 \mathrm{~s}$ for $10 \mathrm{~min}$. Male pupfish often defend contiguous territories, sometimes with a distance of less than $20 \mathrm{~cm}$ from each other. Thus a simultaneous choice scenario between nearby males, such as the one used in this setup, accurately reflects the natural condition. At the end of each replicate, females and males were placed in separate stock tanks and were not used again.

To control for possible side biases in female choice, the position of males and their respective substrates in the end compartments was alternated between replicates.

\section{Experiment I: The effect of substrate quality}

This experiment examined whether females preferred to approach males on a rocky or sandy substrate, when the males were of equal size. Preferences were measured in threecompartment aquaria as described above. All three compartments had sand on the bottom, and a small rock was placed in one of the end compartments.

To control for the possibility that females would approach the compartment with the rock independently of the presence of the male, the experiment was repeated without any fish in the two end compartments.

Each fish was only used once for each replicate, and different females were used for the experiment and the control. Fourteen replicates were conducted in the experimental condition (with males present) and 13 in the control condition (no males).

\section{Experiment II: The effect of male size}

This experiment examined whether females preferred larger males independently of substrate quality.

Experimental aquaria were set up as described above. All substrate was sand, which we chose rather than rocks because small differences in the microtopographic heterogeneity of 
rocks may affect their attractiveness to females (Kodric-Brown, 1983). Two males of different sizes (see above) were placed in the end compartments after the female had been in the tank for $24 \mathrm{~h}$. The placement of the males in each compartment was alternated between replicates, with the smaller male on the left side for one choice trial and on the right side for the next. After the males had been habituated, we removed the opaque partitions and recorded the position of the female within the three central sections, as described above.

In order to further control for possible side preferences, we repeated the experiment, using different females, without any males in the end compartments. We used a sample size of 14 replicates for the experimental condition, and 7 for the control. The reason for the decrease in the number of control trials was an outbreak of disease among the fish, which caused considerable mortality and decreased our stock numbers.

Experiment III: The relative importance of male size and substrate quality

This experiment tested the relative impacts of substrate quality and male size on female preferences, by giving females a choice between a large male on a low-quality (sand) substrate and a small male on a high-quality (rock) substrate.

Experimental aquaria were set up as described above. Both end compartments had sand bottoms, but only one had a rock. The center compartment had only sand. After a female had occupied the center compartment for $24 \mathrm{~h}$, a large male was placed in the sand-only compartment, and a smaller male was placed in the compartment with the rock. To control for a possible female side bias, we alternated the placement of the males and substrates in each compartment between replicates. Sixteen replicates were run. Because of the limited number of available animals, the size difference between the males was slightly less than $15 \%$ in two replicates.

\section{Statistical note}

\section{Field data}

Nonparametric tests from Siegel \& Castellan (1988) were used in all analyses because the data were not normally distributed and did not meet the assumptions for parametric tests. Data from both years for each locality were pooled for statistical analyses. Mann-Whitney $U$-tests (Siegel \& Castellan, 1988) were used to compare the two variables between different years for males on rocks and males on silt in both localities. All Mann-Whitney tests were two-tailed. No significant differences were found in any variables between years for males on rocks and males on silt, and variables such as water temperature, depth and habitat topography did not vary between years.

\section{Laboratory experiments}

Because the time a female spent in close proximity to each male was not independent, matched scores for time spent by the females adjacent to each male were analyzed by (twotailed) Wilcoxon signed-ranks tests (see Siegel \& Castellan, 1988). The relationship between male size and female association time was assessed by Spearman rank correlation. 


\section{Results}

Mating success and size distribution of males in the wild

Figure 1 shows the mating success of males on rocks versus on silt at both field sites. Males on rocks received significantly more spawns than males on silt (for males in Escobedo: Mann-Whitney $U=202, z=-2.07$, $p=0.038$. For males in la Becerra: $U=169, z=-2.74, p=0.006$,
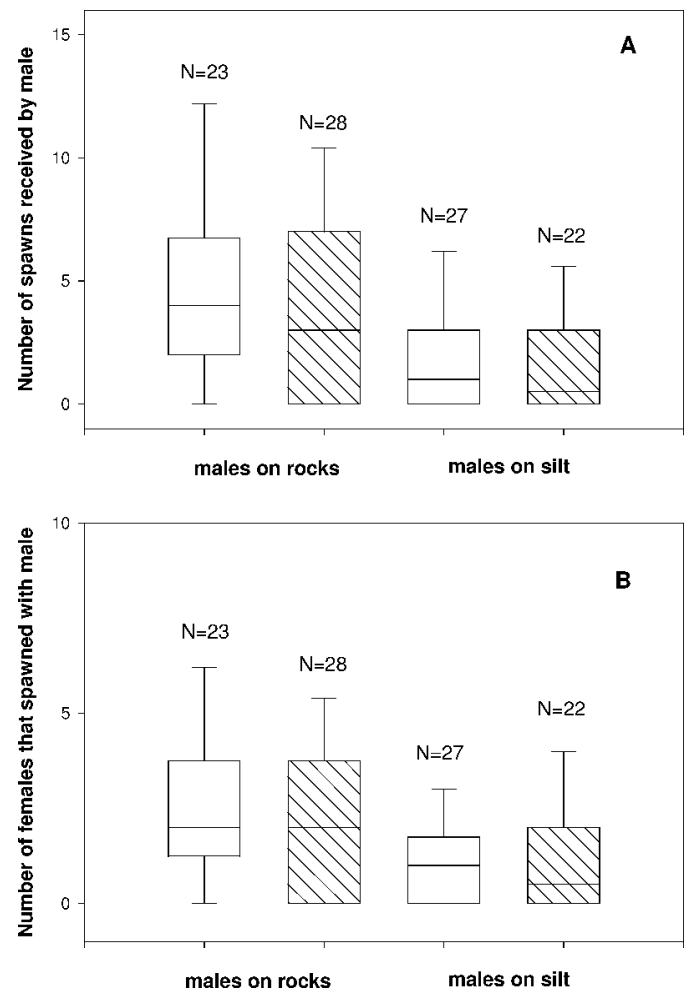

Fig. 1. Reproductive success of males on rocks versus silt at two localities, estimated by (A) the number of spawnings received by each male, and (B) the number of females that spawned with each male. The clear boxes indicate males from La Becerra, and the hatched boxes indicate males from Escobedo. Males on rocks received significantly more spawnings than males on silt in both localities (Mann-Whitney $U=202, z=-2.07, p=0.038$ for Escobedo and $U=169, z=-2.74, p=0.006$ for La Becerra). Males on rocks mated with significantly more females than males on silt in La Becerra (Mann-Whitney $U$-test $U=157$, $z=-2.98, p=0.002)$, and this trend was present but not significant in Escobedo $(U=222$, $z=-1.67, p=0.09)$. The boxes represent medians and $1^{\text {st }}$ and $3^{\text {rd }}$ quartiles. The lines represent $10^{\text {th }}$ and $90^{\text {th }}$ percentiles. 
Fig. 1A). Males on rocks in La Becerra also mated with significantly more females than males on silt $(U=157, z=-2.98, p=0.002$, Fig. 1B), and this trend was present but not significant in Escobedo $(U=222, z=-1.67$, $p=0.09$, Fig. 1B). Females often spawned repeatedly with a single male (in one visit), and they spawned significantly more times per visit with males on rocks than with males on silt in Escobedo $(U=211, z=-1.95, p=0.05)$.

Differences in mating success were not associated with differences in male size. Male size (estimated categorically) was not correlated with the total number of females spawning with him (Spearman $r_{\mathrm{s}}=0.00, N=37$, $p=0.99$ in La Becerra and $r_{\mathrm{s}}=0.208, N=46, p=0.164$ in Escobedo), nor with the total number of spawns received by each male $\left(r_{\mathrm{s}}=0.018\right.$, $N=37, p=0.914$ in La Becerra, and $r_{\mathrm{s}}=0.186, N=46, p=0.164$ in Escobedo). The frequency distribution of size classes of males defending each type of substrate is shown in Table 1. All of the males observed fell into the size categories II, III and IV. No males in the size categories I (3-4 cm) and $\mathrm{V}(7-8 \mathrm{~cm})$ were observed.

We found no significant difference in the size classes of males defending rocks versus silt territories in La Becerra ( $G$-test, Sokal \& Rohlf, 1995: $G$ adjusted using William's correction $=0.184$, df $=2, p>0.05$; see Table 1). However, the frequency distribution of size classes in Escobedo was significantly different for males on rocks versus on silt/sand territories $\left(G_{\text {adj }}=8.24, \mathrm{df}=2, p<0.025\right.$; see Table 1$)$.

TABLE 1. Frequency distribution of size classes of males defending rock territories versus silt/sand territories in two localities (Escobedo and La Becerra)

\begin{tabular}{lcc}
\hline Size category & $\begin{array}{c}\text { Number of males on } \\
\text { rock territories }\end{array}$ & $\begin{array}{c}\text { Number of males on } \\
\text { silt territories }\end{array}$
\end{tabular}

Escobedo

II $(4-5 \mathrm{~cm})$

III $(5-6 \mathrm{~cm})$

IV $(6-7 \mathrm{~cm})$

La Becerra

II $(3-4 \mathrm{~cm})$

III $(4-5 \mathrm{~cm})$

IV $(6-7 \mathrm{~cm})$

The numbers in the columns represent the number of males in each size-class observed on each of the two substrate types. 


\section{Experiment I: Preference for habitat quality}

Females spent significantly more time in close proximity to the male whose compartment conatined a rock than with males on sand alone (Wilcoxon $T=105, p=0.0002, N=14$, Table 2). By contrast, when the experiment was repeated with no males in the end compartments, females spent significantly more time in close proximity to the sandy compartment (Wilcoxon $T=80.5, p=0.0124, N=13$, Table 2).

TABLE 2. Results from experiments examining female association preferences for different traits

\begin{tabular}{|c|c|c|c|c|c|}
\hline & $\begin{array}{l}\text { median time } \\
\text { (5 s units) }\end{array}$ & $\begin{array}{c}1^{\text {st }} \\
\text { quartile }\end{array}$ & $\begin{array}{c}3^{\text {rd }} \\
\text { quartile }\end{array}$ & $N$ & $p$ \\
\hline \multicolumn{6}{|l|}{$\begin{array}{l}\text { Experiment 1: } \\
\text { substrate preference }\end{array}$} \\
\hline Male on rock & 67.5 & 60 & 79.75 & 14 & 0.0002 \\
\hline Male on sand & 21.5 & 19 & 31.75 & & \\
\hline Rock only & 38 & 28 & 45 & 13 & 0.0124 \\
\hline Sand only & 56 & 50 & 77 & & \\
\hline \multicolumn{6}{|l|}{$\begin{array}{l}\text { Experiment } 2 \text { : } \\
\text { size preference }\end{array}$} \\
\hline Large male & 62 & 49.25 & 71.75 & 14 & 0.0030 \\
\hline Small male & 36 & 25.5 & 45 & & \\
\hline \multicolumn{6}{|l|}{$\begin{array}{l}\text { Experiment } 3 \text { : } \\
\text { size } v s \text { substrate }\end{array}$} \\
\hline Small male on rock & 43 & 31.75 & 62.75 & 16 & NS \\
\hline Large male on silt & 50.5 & 30.75 & 67.25 & & \\
\hline \multicolumn{6}{|l|}{ Control for side bias: } \\
\hline Left & 35 & 26.5 & 43.5 & 7 & NS \\
\hline Right & 45 & 39.5 & 51.5 & & \\
\hline
\end{tabular}

Experiment 1 examined female association preferences for males on two different types of substrate; experiment 2 examined female association preferences for different sized males, and experiment 3 examined the choice of females when male size and substrate preferences were pitted against each other. The first column denotes the median time spent by the female in close proximity to each male; the second and third columns denote the $1^{\text {st }}$ and $3^{\text {rd }}$ quartiles, respectively, the fourth column denotes the sample size of each experiment, and the fifth column denotes the significance level at which we rejected the null hypothesis. 
Experiment II: Preference for male size

Females associated preferentially with the larger male (Wilcoxon $T=97$, $p=0.0030, N=14$, Table 2 ). With no males in the end compartments, females did not exhibit a side preference (Wilcoxon $T=20.5, p=0.375$, $N=7$, Table 2).

\section{Experiment III: Preference for male quality versus substrate quality}

Ten of 16 females spent more than $50 \%$ of their time with the larger male, on sand, and 6 spent more time with the smaller male, whose compartment contained a rock (binomial test, $p=0.122$ ). In three cases, the females divided their time almost equally between the options. Overall, there was no significant difference in the time that females spent with one choice or the other (Wilcoxon signed ranks test: $z=0.4136, p=0.67, N=16$, Table 2).

It is possible that females were more likely to show a preference when the size difference between males was large. We expected the difference in the time spent by females inspecting each male to increase as the size differences between males increased, but although we did find such a trend, there was no significant correlation between the male pair's size difference and the female's time allocation difference $\left(r_{\mathrm{s}}=-0.46, p=0.07\right)$.

\section{Discussion}

In resource-based polygynous breeding systems where males acquire matings mainly by defending a resource essential to reproduction, male mating success is expected to be positively correlated with the quality of the defended resource (Kodric-Brown, 1983). This prediction was supported in natural populations of the twoline pupfish: males defending territories on rocks had significantly higher mating success than males defending territories on silt and sand.

Other Cyprinodon studies have also revealed a female preference to spawn on rocky substrates (Kodric-Brown, 1977, 1978, 1983), but both our field results and previous studies of pupfish in the wild may have failed to detect a possible confounding effect of body size in the preference for rocks. For example, if males defending rocky substrates are typically larger, females may be selecting for large males and not the rocky substrates. Kodric-Brown 
(1978) found that males on rocks were typically larger than males defending territories on other substrates, and our field observations revealed that in one locality, males on rocks were larger than males defending sand and silt territories. However, our method for estimating male size in the field may not have been sufficiently accurate to estimate any bias towards larger males defending the rock territories. Similarly, the lack of a correlation between male size and mating success in the field may also have resulted from the inaccuracy of our field measurements of male size.

The laboratory experiments did reveal a female association preference for larger males when substrate quality was held constant. It is possible that a preference for size that went undetected in the field was observed in this experiment because male sizes used in this experiment were below the resolution of the field estimates.

Although females preferred to approach larger males in the laboratory, this preference did not become more pronounced as size differences between the males increased. One possibility is that females were avoiding the largest males because of a tendency to mate assortatively with respect to size. Such size-assortative female choice has been found in other pupfish (KodricBrown, 1977).

The experiments also revealed a female association preference for males on a rocky substrate, suggesting that the female preference for rocks exists independent of male body size. Since females did not prefer the rock habitat in the absence of males, we conclude that they were not simply attracted to the habitat. In fact, in the absence of male defenders, females preferred the sandy compartment. Quite possibly, in the absence of mating opportunities, females may be attracted to the sand for feeding opportunities and because their light coloration is most cryptic over sandy substrates.

\section{The role of habitat}

The possible advantages for females that spawn on rocks as opposed to silt are most likely related to egg survival. While rocks provide visual landmarks for efficient territorial defense and orientation, as well as food resources, they also have numerous crevices used by females to deposit eggs (KodricBrown, 1983). Females may prefer to spawn on rocks because such crevices provide a better substrate for the eggs to adhere, and protection to eggs from conspecific cannibalism (Kodric-Brown, 1977). Conversely, eggs deposited in silt territories may suffer from increased mortality from lack of aeration by being silted in, a common source of egg mortality (Kinne \& Kinne, 1962). 
The role of size

Many female fishes prefer to approach large males (Ryan et al., 1990; McPeek, 1992; Schlupp et al., 1994; Marler \& Ryan, 1997; Ptacek \& Travis, 1997; Witte \& Ryan, 1998), and male size in pupfish appears to be an important predictor of competitive ability (Kodric-Brown, 1978; Draud, 1996). Some of our preliminary results showed that larger males won 12 of 15 contests over rocks (A.M. Ludlow, unpubl. data). These results match those of Kodric-Brown's (1978) field experiments, in which Pecos pupfish males that attempted to defend territories on introduced rocks were quickly displaced by larger males. Draud (1996), using the variegated pupfish, also found that larger males typically win contests. The competitive advantage of larger males may benefit females in terms of reduced interference during spawning. For example, females may prefer larger males because larger males defend larger territories, and there is less interference during spawning from adjacent territory holders in larger territories (Itzkowitz, 1981).

Females may also prefer larger males because they are more efficient in defending eggs (e.g. Downhower \& Brown, 1980; Bisazza \& Marconato, 1988; Cote \& Hunte, 1989) and are less likely to eat their own eggs (Downhower \& Brown, 1980; Sargent, 1988), or because of a female sensory bias (Ryan \& Keddy-Hector, 1992).

\section{Which is more important: male size or type of substrate?}

When females were faced with a trade-off between choosing a large male guarding a low-quality substrate and a smaller male guarding a high-quality substrate, their responses showed considerable variation. Some females spent more time with the larger male, while others approached the smaller male more. In a few cases, females divided their time between the two males, without showing any preference.

There are several possible (and not mutually exclusive) interpretations for the lack of a clear preference in this experiment. First, the two traits (male size and substrate type) may be of roughly similar importance to females. This idea is supported by a previous study (Itzkowitz, 1978) which showed that in a homogeneous habitat with similar sized males, female variegated pupfish spawned randomly. A second possibility is that some females may give priority to the size stimuli while other females may prefer substrate type over male size. Further experiments examining the consistency 
(repeatability) of individual females' preferences would be required to test this idea.

It is also possible that females use male size to discriminate between males on less preferred habitats, such as sand and silt. One possible way to test this idea would be to assess female response to male size over different substrates. With male sizes and size disparity held constant, this idea would be supported if the preference for larger males were stronger on the less preferred habitat.

Finally, females may also use other male traits that were not considered in this study. Although male color is an important determinant of male mating success in other Cyprinodon (Kodric-Brown, 1983), individual differences in male color intensity in the twoline pupfish are difficult to quantify because body color was barely perceptible by the naked eye, and these fish lack the typical iridescent blue coloration of other pupfish.

In conclusion, female mate choice in the twoline pupfish involves assessment of at least two independent male traits by females: substrate quality and male size. Although field observations only identified substrate quality as a predictor of male mating success, the laboratory experiments revealed a female preference for larger males. Further work is required to determine whether the quantitative differences in rock quality influence female preferences in similar ways to the quantitative differences in male size.

\section{References}

Andersson, M. (1994). Sexual selection. - Princeton University Press, Princeton, N.J.

Backwell, P.R.Y. \& Passmore, N.I. (1996). Time constraints and multiple choice criteria in the sampling behaviour and mate choice of the fiddler crab, Uca annulipes. - Behav. Ecol. Sociobiol. 38, p. 407-416.

Bisazza, A. \& Marconato, A. (1988). Female mate choice, male-male competition and parental care in the river bullhead, Cottus gobio L. (Pisces, Cottidae). - Anim. Behav. 36, p. 1352-1360.

_ _ , _ — \& Marin, G. (1989). Male competition and female choice in Padogobius martensi (Pisces, Gobiidae). - Anim. Behav. 38, p. 406-413.

Cote, I.M. \& Hunte, W. (1989). Male and female mate choice in the redlip blenny - why bigger is better. - Anim. Behav. 38, p. 78-88.

Dale, S. \& Slagsvold, T. (1996). Mate choice on multiple cues, decision rules and sampling strategies in female pied flycatchers. - Behaviour 133, p. 903-944.

Downhower, J.F. \& Brown, L. (1980). Mate preferences of female mottled sculpins, Cottus bairdi. - Anim. Behav. 28, p. 728-734. 
Draud, M.J. (1996). Female mate choice and male-male competition in the variegated pupfish Cyprinodon variegatus. — PhD dissertation, Lehigh University.

Gabor, C. (1999). Association patterns of sailfin mollies (Poecilia latipinna): alternative hypotheses. - Behav. Ecol. Sociobiol. 46, p. 333-340.

Itzkowitz, M. (1978). Female mate choice in the pupfish, Cyprinodon variegatus. - Behav. Proc. 3, p. 1-8.

- - (1981). The relationships of intrusions and attacks to territory size and quality in the pupfish, Cyprinodon variegatus Lacépède. - Biol. Behav. 6, p. 273-280.

Kinne, O. \& Kinne, E.M. (1962). Rates of development in embryos of a Cyprinodont fish exposed to different temperature-salinity-oxygen combinations. - Can. J. Zool. 40, p. 231-253.

Kodric-Brown, A. (1977). Reproductive success and the evolution of breeding territories in pupfish (Cyprinodon). - Evolution 31, p. 750-766.

- - (1978). Establishment and defence of breeding territories in a pupfish (Cyprinodontidae: Cyprinodon). - Anim. Behav. 26, p. 818-834.

- - (1983). Determinants of male reproductive success in pupfish (Cyprinodon pecosensis). - Anim. Behav. 31, p. 128-137.

- _ (1993). Female choice of multiple male criteria in guppies — interacting effects of dominance, coloration and courtship. - Behav. Ecol. Sociobiol. 32, p. 415-420.

Lifjeld, J.T. \& Slagsvold, T. (1988). Female pied flycatchers Ficedula hypoleuca choose male characteristics in homogeneous habitats. - Behav. Ecol. Sociobiol. 22, p. 27-36.

Ludlow, A.M. (2000). Sexual Selection in the Cuatro Cienegas pupfish; mate choice and hybridization in Cyprinodon atrorus and Cyprinodon bifasciatus. - $\mathrm{PhD}$ dissertation, Lehigh University.

McPeek, M.A. (1992). Mechanisms of sexual selection operating on body size in the mosquitofish (Gambusia holbrooki). - Behav. Ecol. 3, p. 1-12.

Marler, C.A. \& Ryan, M.J. (1997). Origin and maintenance of a female mating preference. - Evolution 51, p. 1244-1248.

Petersen, C.W. (1988). Male mating success, sexual size dimorphism, and site fidelity in two species of Malacotecnus (Labrisomidae). — Env. Biol. Fish. 21, p. 173-183.

Price, T.D. (1984). Sexual selection on body size, territory and plumage variables in a population of Darwin's finches. - Evolution 38, p. 327-341.

Ptacek, M.B. \& Travis, J. (1997). Mate choice in the sailfin molly, Poecilia latipinna. Evolution 51, p. 1217-1231.

Ryan, M.J., Hews, D.K. \& Wagner, W.E. (1990). Sexual selection on alleles that determine body size in the swordtail Xiphophorus nigrensis. - Behav. Ecol. Sociobiol. 26, p. 231 237.

— — \& Keddy-Hector, A. (1992). Directional patterns of female mate choice and the role of sensory biases. - Amer. Nat. 39, p. S4-S35.

Sargent, R.C. (1988). Paternal care and egg survival both increase with clutch size in the fathead minnow, Pimephales promelas. - Behav. Ecol. Sociobiol. 23, p. 33-37.

Schlupp, I., Marler, C. \& Ryan, M.J. (1994). Benefit to male sailfin mollies of mating with heterospecific females. - Science 263, p. 373-374.

Siegel, S. \& Castellan, N.J.Jr. (1988). Nonparametric statistics for the behavioral sciences, $2^{\text {nd }}$ ed. - McGraw-Hill, New York.

Sokal, R.R. \& Rohlf, F.J. (1995). Biometry, $3^{\text {rd }}$ ed. - W.H. Freeman and Company, New York. 
Thompson, S. (1986). Male spawning success and female choice in the mottled triplefin, Forsterygion varium (Pisces: Tripterygiidae). — Anim. Behav. 34, p. 580-589.

Thornhill, R. (1983). Cryptic female mate choice and its implications in the scorpionfly Harpobittacus nigriceps. - Am. Nat. 122, p. 765-788.

Witte, K. \& Ryan, M.J. (1998). Male body length influences mate-choice copying in the sailfin molly Poecilia latipinna. - Behav. Ecol. 9, p. 534-539. 